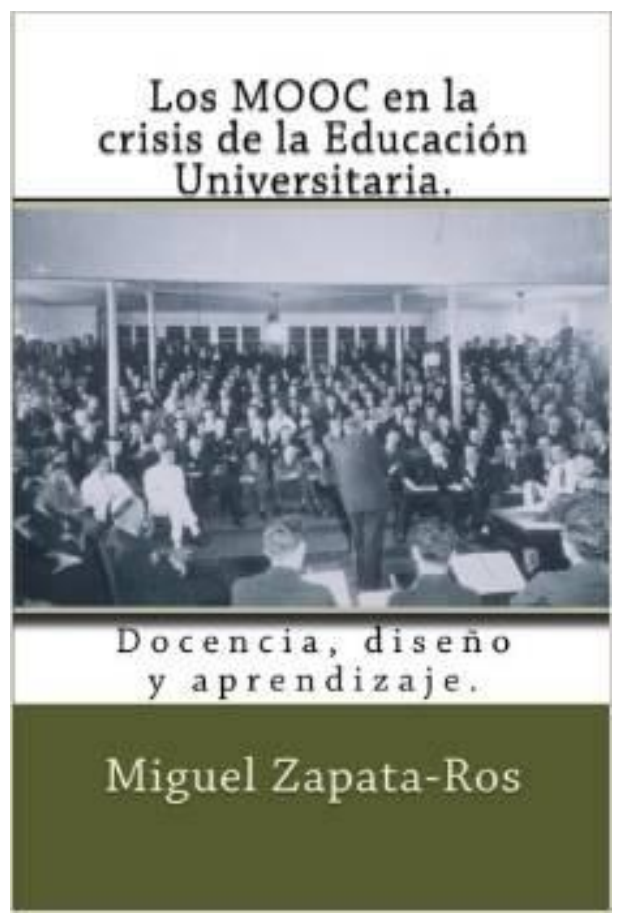

\title{
"MOOCs in the Higher Education crisis", book critique
}

Charles Reigeluth

Miguel Zapata-Ros is among the most active and prolific researchers in the field of open education and distance learning. He has written extensively about these topics in books, articles, blogs, and social media and has participated in multiple international conferences. It was a pleasure to finally meet him in Madrid in July 2013.

In his book, Zapata-Ros (2014) addresses a controversial trend in distance education, the massive open online courses (MOOCs). Praised by some scholars, highly criticized by others, the fact is that, as the author affirms, MOOCs are here to stay. An elaborate concoction of social, economic, and technological factors has made possible the exponential expansion of these courses: steady increase in college tuition rates, devaluation of college degrees, an uncertain job market, and more abundant networks of distributed knowledge.

Part of the quandary about the effectiveness of MOOCs is that, in spite of being a relatively new educational approach, nowadays there are quite a few different varieties of MOOCs, varying in such critical instructional elements as the level of collaboration among students, type of interaction with instructor or mentors, number of students, amount of feedback provided, and hands-on opportunities.

In his book, the Zapata-Ross dives deep into different aspects of MOOCs, conducting an exhaustive analysis of multiple sources such as blogs, social networks, interviews, and articles. It describes the role of the major players in the evolution of MOOCs (individuals, universities, and corporations) and the way they have influenced other universities and institutions around the world, making it a global phenomenon.

The author also presents an evidence-based critical review about the substantial lack of fundamental instructional elements that some existing MOOCs have, thus causing a high attrition rate. Research has demonstrated that, in order to promote learning, it is critical to provide practice opportunities to students with immediate feedback for diverse situations (Merrill, Reigeluth, \& Faust, 1979). Still, many MOOCs limit themselves to just presenting information, either as a set of video clips or written text following a "spray-and-pray-remember-what-I-say" type of instruction (Merrill, 2009). As such, these types of MOOCs should be intended to complement or supplement other types of instruction, instead of replacing them.

This is a thought-provoking book. After a thorough analysis of learning and instructional theories, the author puts forward several suggestions that could increase the effectiveness of MOOCs, such as: following a proposed instructional design, making content duration flexible, and using data mining techniques to personalize learning. 
I highly recommended this book for those who have considered implementing a MOOC - faculty, staff, and administrators. It is also a useful read for instructors who are already offering them and are open to suggestions for enhancing the learning experience of their students.

Concluido en 2014

Reigeluth, C. M. (2019). "MOOCs in the Higher Education crisis", book critique. RED Revista de Educación a Distancia, Reseñas.

DOI: http://dx.doi.org/10.6018/red/resenas/04

Note: I am grateful to Miguel Lara at California State University at Monterey Bay for his role in preparing this critique.

\section{References.-}

Zapata-Ros, M. (2014) Los MOOC en la crisis de la Educación Universitaria. Docencia, diseño y aprendizaje. Amazon. 